\title{
Surface characterization of activated alumina powder through the mechano-chemical treatment for fabrication of non-fired ceramics
}

\author{
Takashi SHIRAI, ${ }^{*}$ Apiluck EIAD-UA, ${ }^{* * *}$ Tran Thi Thu HIEN,*** and Masayoshi FUJI ${ }^{*, \dagger}$ \\ *Advanced Ceramics Research Center, Nagoya Institute of Technology, 3-101-1, Honmachi, Tajimi, Gifu 507-0033, Japan \\ ${ }^{* *}$ College of Nanotechnology, King Mongkut's Institute of Technology (KMITL), 1 Soi Chalongkrung 1, Ladkrabang, Bangkok 10520 \\ ${ }^{* * *}$ School of Materials Science and Technology, Hanoi University of Science and Technology, \\ 312C5 Ist Dai Co Viet, Hai Ba Trung, Hanoi
}

\begin{abstract}
Functional ceramics were synthesized using ceramic powders activated by mechanochemical processing. The activated powders were dispersed in an alkali-containing solvent to dissolve the metallic ions at the powder surface and effect re-precipitation between the grains. The "non-firing ceramic process" afforded high-strength ceramic solids without the need for calcination. The key step in this technique is surface activation of the ceramic powders through mechanochemical processing. We investigated the bonding and activity of the atoms near the surface by spectroscopic analysis of desorption of the adsorbed water molecules, a convenient and quantitative method. The powder surface contained an increased number of uncoordinated defects after mechanochemical processing, and powders with high compact strength showed high activity and had high surface $\mathrm{Al}^{\mathrm{V}}$ content. Diffuse reflectance infrared Fourier transform measurements of the desorption of water molecules allowed for easy and rapid determination of differences in the surface activity, which was not possible when using alternative analysis methods.
\end{abstract}

(C)2012 The Ceramic Society of Japan. All rights reserved.

Key-words: Mechanochemical, Surface activation, Adsorbed water molecules, Coordinatively unsaturated site

[Received April 23, 2012; Accepted August 19, 2012]

Mechanochemical processing ${ }^{1)-4)}$ has recently been used to synthesize hybrid particles and for calcination at low temperature. In this process, mechanical energy is applied (by using a planetary ball mill, for example) to the raw-material powder, such that excess energy is accumulated at the surface and interior of the powder. Physical changes to the material, such as an increase in surface area or formation of lattice defects and mismatch strains, will lead to an increase in the surface energy, and consequently, to chemical changes such as increased reactivity or the formation of new phases. Methods for the quantitative estimation of the powder-surface activity have not yet been established; therefore, the unreliable quality resulting from the uneven application of mechanochemical effects poses a problem.

Our group took advantage of the high chemical activity of mechanochemically treated particles that are dispersed in alkalicontaining solvents for dissolving the metallic ions at the powder surface. ${ }^{5-7)}$ The precipitates formed between the residual grains result in solidification. Hence, we are developing a method to obtain solids similar to fired ceramics but without calcination (non-fired ceramics). ${ }^{5-7)}$ The key step in this method is surface activation of the ceramic powders through mechanochemical processing. We have attempted to activate the powder surface by applying mechanical energy, for example, by planetary ball milling; however, there is no established method for quantitatively investigating the surface activation after mechanochemical processing and evaluating the effects of mechanochemical processing on the powder surface.

This paper reports the properties of alumina particles mechanochemically processed under various conditions and discusses the mechanical properties of the solidified compacts that were dispersed in a solvent $(\mathrm{KOH})$. The surface of the mechanochemi-

\footnotetext{
Corresponding author: M. Fuji; E-mail: fuji@nitech.ac.jp
}

cally processed alumina powder is evaluated by diffuse reflectance infrared Fourier transform (DRIFT) measurements, and the relationship between the powder surface and the compact properties is reported.

The samples used in this study were commercially available sub-micron high purity $\alpha$-alumina particles with an average grain size of $0.6 \mu \mathrm{m}$ (AL-160-SG4, Showa Denko). The characteristics of the $\alpha$-alumina powder supplied by the manufacturers complemented with the data obtained in this work are shown in Table 1. Mechanochemical processing was performed by planetary ball milling (pulversettle 5, Fritsch, Germany) using zirconia ball and pot. Activated powders were prepared under the following conditions: revolution rate, 100, 150, 200, 250, and $300 \mathrm{rpm}$; milling time, 10, 20, 40, and $60 \mathrm{~min}$; ball size, 1, 2, 3, 5, 10 , and $15 \mathrm{~mm}$. A slurry of $30 \mathrm{vol} \%$ powder was obtained from the activated powder using a $3 \mathrm{~mol} / \mathrm{L} \mathrm{KOH}$ solution. This slurry was poured into a Teflon mold $(\phi 20 \times \mathrm{t} 10 \mathrm{~mm})$, sealed, and retained for $24 \mathrm{~h}$ at room temperature to effect solidification. The solidified material was removed from the mold and dried at $40^{\circ} \mathrm{C}$ for $24 \mathrm{~h}$. The strength of the compact was evaluated with five

Table 1. The characteristics of the $\alpha$-alumina powder supplied by the manufacturers

\begin{tabular}{|c|c|c|}
\hline \multicolumn{2}{|c|}{ Powder } & $\alpha-\mathrm{Al}_{2} \mathrm{O}_{3}$ \\
\hline \multicolumn{2}{|c|}{ Grades } & AL-160SG-4 \\
\hline \multirow{5}{*}{$\begin{array}{c}\text { Chemical } \\
\text { composition } \\
/ \%\end{array}$} & $\begin{array}{c}\left.\text { L.O.I }{ }^{*} 1\right) \\
\left(0-1100^{\circ} \mathrm{C}\right)\end{array}$ & 0.35 \\
\hline & $\mathrm{SiO}_{2}$ & 0.02 \\
\hline & $\mathrm{Fe}_{2} \mathrm{O}_{3}$ & 0.01 \\
\hline & $\mathrm{Na}_{2} \mathrm{O}$ & 0.06 \\
\hline & $\mathrm{Al}_{2} \mathrm{O}_{3}$ & 99.56 \\
\hline
\end{tabular}

\footnotetext{
${ }^{* 1)}$ : Loss of Ignition.
} 

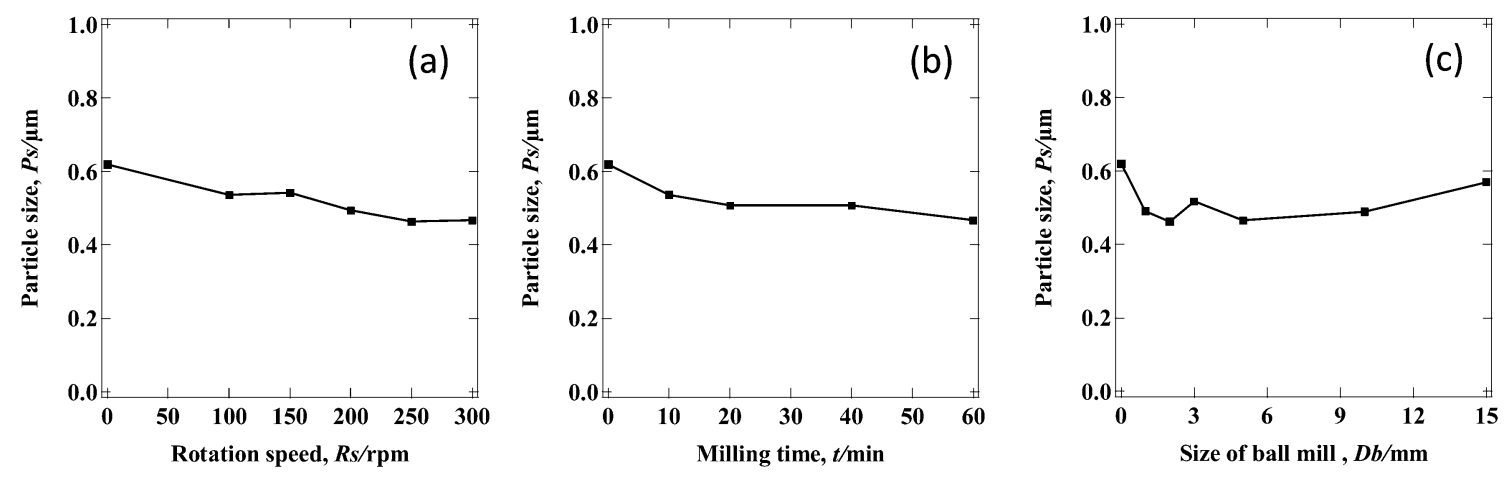

Fig. 1. The average particle size of the powder samples measured after various mechanochemical processes; (a) rotation speed, (b) milling period, and (c) size of balls.

samples for each condition by a diametral compression test ${ }^{8)}$ conducted using a universal testing machine (AGS-G, Shimadzu) at a crosshead speed of $0.1 \mathrm{~mm} / \mathrm{s}$ and a sampling time of $0.05 \mathrm{~s}$. The stress at fracture, $S_{t}$ (tensile strength), was obtained from the load at fracture $P$ using the following equation:

$$
S_{t}=\frac{2 P}{\pi d l}
$$

Here, $P$ is the total load $(\mathrm{N})$; $d$, the diameter of the compact (m); and $l$, the thickness of the compact (m).

The surface of the powder after mechanochemical processing was evaluated by DRIFT spectroscopy. The powder sample was maintained in a sealed container for $48 \mathrm{~h}$ at a relative humidity of $100 \%$ and then subjected to measurements in $\mathrm{N}_{2}$ atmosphere and in vacuum $\left(2.7 \times 10^{-3} \mathrm{~Pa}\right)$ with heating to $200^{\circ} \mathrm{C}$. Spectra were measured before and after desorption of the water molecules adsorbed on the surface, and the difference spectrum was calculated. The particle size was measured using a particle size distribution measuring instrument (MT3000II, Nikkiso).

Figure 1 shows the average particle size of the powder samples that was measured after various mechanochemical processes. The average particle size of the mechanochemically processed powder was smaller than that of the unprocessed powder and decreased slightly with an increase in the revolution rate, milling time, and ball size. Figure 2 shows the tensile strengths of the compacts obtained after diametral compression. The results under varied conditions are shown, whereby the variation in revolution rate is shown in Fig. 2(a), the variation in milling time is shown in Fig. 2(b), and the variation in ball size is shown in Fig. 2(c). In summary, the strength of the sample processed at a revolution rate, milling rate, and ball size of $250 \mathrm{rpm}, 40 \mathrm{~min}$, and $5 \mathrm{~mm}$, respectively, was the highest and more than twice that of the unprocessed sample. Therefore, there exists a set of optimum mechanochemical processing conditions that would decide the strength of the compact.

The activity or state of the powder surface plays a very important role in increasing the strength of the compact after mechanochemical processing. Therefore, we investigated a method for evaluating the activity of the powder. Mechanochemical and powder grinding processes, such as ball milling, involve the application of mechanical energy, where the excess energy disrupts the crystal state (coordination of atoms) at the powder surface. In the case of $\alpha$-alumina, some octahedrally coordinated aluminum ions become $\mathrm{Al}^{\mathrm{IV}}$ or $\mathrm{Al}^{\mathrm{V}}$ coordinated, and coordinatively unsaturated sites (CUS) are formed. ${ }^{9)-13)}$ CUS are highly active and can readily adsorb water molecules from the atmosphere, so that hydrates are formed on the surface. ${ }^{14)-16)}$
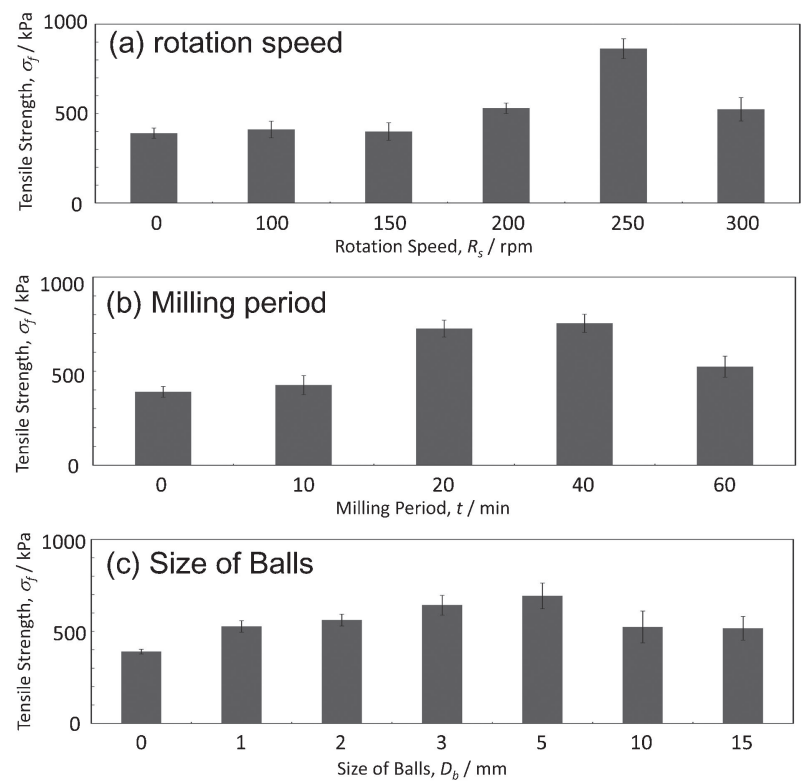

Fig. 2. The tensile strengths of the compacts obtained from diametral compression test; (a) rotation speed, (b) milling period, and (c) size of balls.

Vlaev et al. studied the nature and reactivity of the hydrate coverage on the surface of $\gamma$-alumina. ${ }^{11)}$ They concluded that the absorption bands in the $1350-1640 \mathrm{~cm}^{-1}$ region are attributable to water molecules physically or coordinately bonded to incompletely coordinated aluminum ions on the oxide surface. Furthermore, specific spectral assignments were made: the water molecules coordinated to tetrahedral or octahedral aluminum ions were characterized by the absorption bands at 1380 and $1580 \mathrm{~cm}^{-1}$, respectively, whereas those forming the pairs $\mathrm{Al}^{\mathrm{IV}}$ $\mathrm{Al}^{\mathrm{VI}}$ and $\mathrm{Al}^{\mathrm{VI}}-\mathrm{Al}^{\mathrm{VI}}$ have a band at $1460 \mathrm{~cm}^{-1}$. Physically adsorbed water in the form of associations of molecules gave an absorption band at $1640 \mathrm{~cm}^{-1}$. Shirai et al. reported the state of molecular water adsorbed on the surface of as-received commercial high-purity $\alpha-\mathrm{Al}_{2} \mathrm{O}^{3}$ powders. ${ }^{12), 13)}$ The visible band at $1530 \mathrm{~cm}^{-1}$ in the difference spectra of the powders produced by the hydrolysis of aluminum alkoxide was assigned to the water molecules coordinated to $\mathrm{Al}^{\mathrm{V}}$ ions. ${ }^{9), 12)}$

Hence, we focused on the adsorption and desorption behavior of water molecules at the CUS. Using a spectroscopic technique, we conveniently and quantitatively evaluated the bonding and activity of the atoms near the powder surface before and after the mechanochemical and milling processes. 

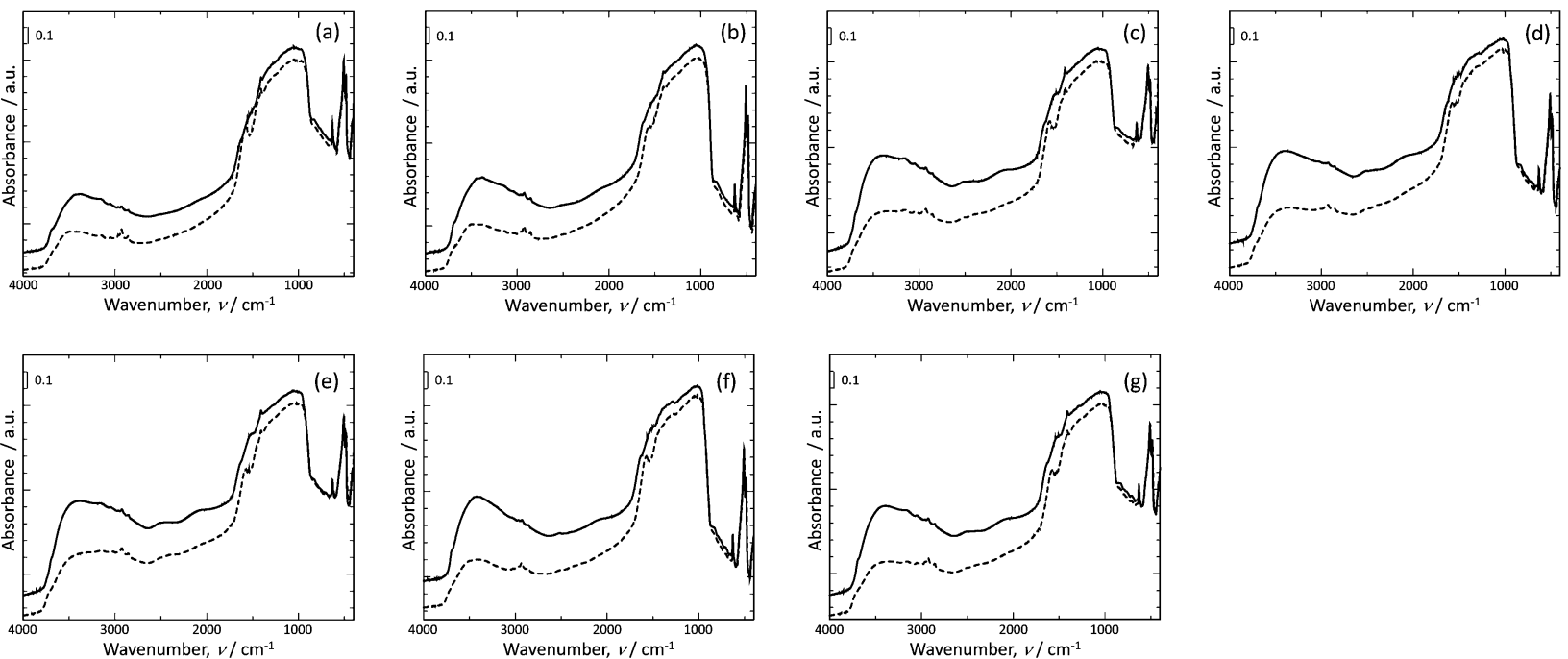

Fig. 3. Hydroxyl stretching and bending absorption frequency region showing DRIFT spectra recorded at room temperature under $\mathrm{N}_{2}$ atmosphere and after heating in situ under vacuum at $2.7 \times 10^{-3} \mathrm{~Pa}$ up to $200^{\circ} \mathrm{C}$, (a) as received, (b) $100 \mathrm{rpm}$ of rotation speed, (c) $250 \mathrm{rpm}$ of rotation speed, (d) $10 \mathrm{~min}$ of milling period, (e) $40 \mathrm{~min}$ of milling period, (f) $1 \mathrm{~mm}$ of ball, (g) $5 \mathrm{~mm}$ of ball.

Figure 3 shows the DRIFT spectra recorded in $\mathrm{N}_{2}$ atmosphere and under vacuum with heating. The powder samples with the highest (revolution rate: $250 \mathrm{rpm}$, milling time: $40 \mathrm{~min}$, and ball size: $5 \mathrm{~mm}$ ) and lowest strengths (revolution rate: $100 \mathrm{rpm}$, milling time: $10 \mathrm{~min}$, and ball size: $1 \mathrm{~mm}$ ) among those processed under various mechanochemical conditions were considered (Fig. 2). The solid and dashed lines show the spectra recorded in $\mathrm{N}_{2}$ atmosphere and those recorded under vacuum with heating. Difference spectra were obtained, and the relationship between the activation conditions and the surface state was analyzed through comparison with the raw (unprocessed) powder.

Figure 4 shows the difference spectra for the absorption band corresponding to $\mathrm{OH}$ bending. The peaks shown by dashed lines correspond to the adsorption of water molecules: $1640 \mathrm{~cm}^{-1}$, physically adsorbed water; ${ }^{11)} 1580 \mathrm{~cm}^{-1}$, water adsorbed on $\mathrm{Al}^{\mathrm{IV}}$, 11) $1530 \mathrm{~cm}^{-1}$, water adsorbed on $\mathrm{Al}^{\mathrm{V}, 9), 12)} 1460 \mathrm{~cm}^{-1}$, water adsorbed on $\mathrm{Al}^{\mathrm{IV}}-\mathrm{Al}^{\mathrm{VI}}$ and $\mathrm{Al}^{\mathrm{VI}}-\mathrm{Al}^{\mathrm{VI}}$ pairs; ${ }^{11)}$ and $1380 \mathrm{~cm}^{-1}$, water adsorbed on $\mathrm{Al}^{\mathrm{VI}}{ }^{\mathrm{11}}$ ) The peaks were deconvoluted to obtain the intensities of individual peaks. The peak areas are listed in Fig. 5. The peak areas represent the observed increase in each peak. In other words, the number of CUS formed at the surface atoms after the mechanochemical process is shown. The amount of water adsorbed on the CUS was higher in the mechanochemically processed powder; therefore, the number of CUS was speculated to increase because of the change in the state of the powder surface after mechanochemical processing. Furthermore, the amount of water adsorption on the $\mathrm{Al}^{\mathrm{IV}}$ and $\mathrm{Al}^{\mathrm{V}}$ ions increased after mechanochemical processing; therefore, the surface of such powders might be activated because of the disordered atomic arrangement near the surface.

The quantity of adsorption water molecules on the surface CUS increases for the powder milled at $100 \mathrm{rpm}$ in comparison with the raw powder. From these results, the powder surface state changed through the mechanochemical treatment. However, the milled conditions $(100 \mathrm{rpm})$ were not optimized and the changes were not enough for solidification as shown in Fig. 2. The compact with the highest strength had high $\mathrm{A}^{\mathrm{IV}}$ content on the powder surface as shown in Figs. 2 and 5. A possible reason is the more disturbed surface, the more coordination state in the

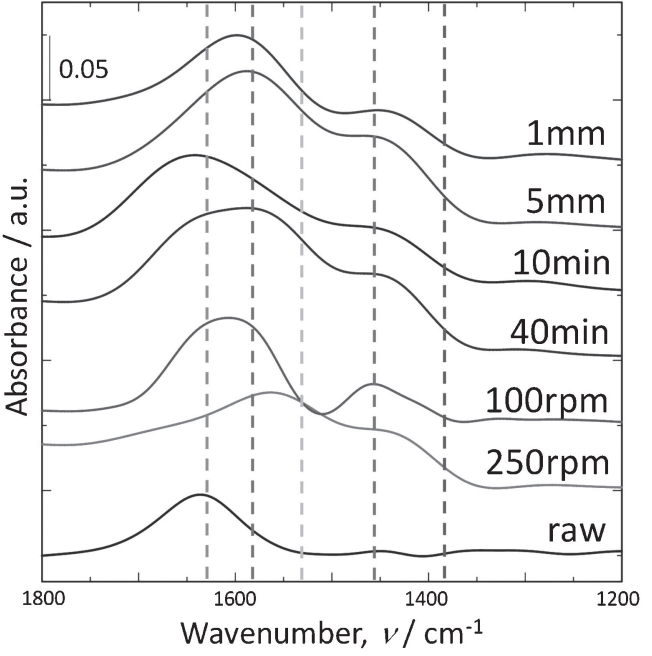

Fig. 4. The differential spectra for absorpion band corresponding to hydroxyl bending region.

surface. It is necessary to examine a surface coordination state and the strength (bonding of particles) relations in the near future. These results show that DRIFT measurement of the adsorption and desorption of water molecules is a very valuable method for evaluating the changes in the powder surface state and activity after mechanochemical processing under different conditions. In particular, the sample with highest mechanical strength had high $\mathrm{Al}^{\mathrm{lV}}$ content, implying that the powder surface was strongly activated.

In the summary, we evaluated the properties of alumina powders mechanochemically processed under various conditions. The optimum mechanochemical processing conditions-revolution rate, milling time, and ball size-under which non-fired ceramic powders with the highest strength could be synthesized were $250 \mathrm{rpm}, 40 \mathrm{~min}$, and $5 \mathrm{~mm}$, respectively. The number of CUS at the powder surface increased after mechanochemical processing. The powder surface of the compact with the highest 


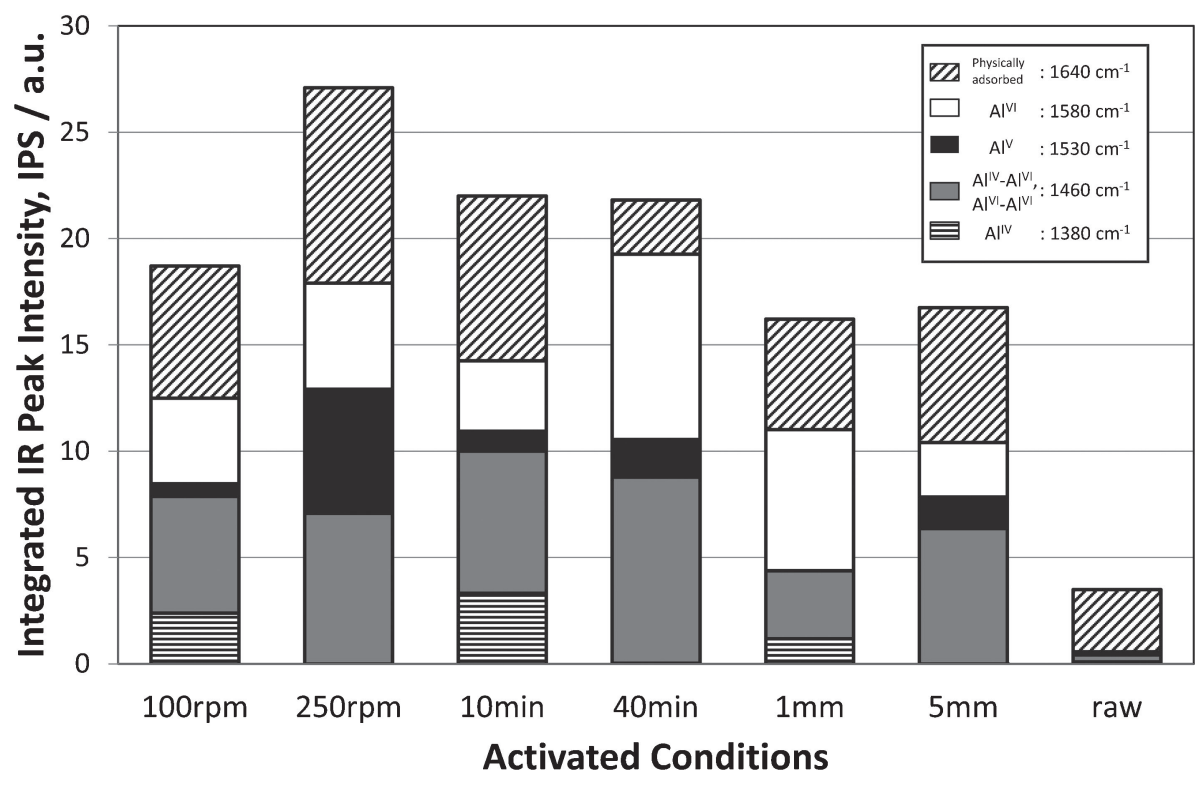

Fig. 5. Comparison of coordinated water molecules intensity, from the spectra given in Fig. 4 .

strength had high $\mathrm{Al}^{\mathrm{V}}$ content, indicating high surface activation. Unlike other analysis methods, DRIFT measurements of the adsorption and desorption of water molecules (as in the present study) allow for the rapid and convenient evaluation of changes in the surface state or surface activity.

\section{References}

1) C. Miclea, C. Tanasoiu, I. Spanulescu, C. F. Miclea, A. Gheorghiu, L. Amarande, M. Cioangher and C. T. Miclea, J. Inf. Sci. Technol., 10, 335-345 (2007).

2) H. Yang, Y. Hu, X. Zhang and G. Qio, Mater. Lett., 58, 387389 (2004).

3) K. Wieczorex-Ciurowa and K. Gamrat, Mater. Sci. Poly, 25, 219-232 (2007).

4) T. Tsuzuki and P. G. McCormick, Acta Mater., 48, 2795-2801 (2000).

5) A. Eiad-ua, T. Shirai, H. Watanabe, M. Fuji, K. Orito and M. Takahashi, Ceram. Trans., 219, 129-135 (2010).

6) A. Eiad-ua, T. Shirai, T. Kato, K. Orito, H. Watanabe, M. Fuji and M. Takahashi, J. Ceram. Soc. Japan, 118, 745-748 (2010).
7) A. Eiad-ua, T. Shirai, H. Watanabe, M. Fuji, K. Orito and M. Takahashi, J. Jap. Soc. Powder Powder Metal, 58, 91-96 (2011).

8) P. Jonsen, H. A. Haggblad and K. Sommer, Powder Technol., $176,148-155$ (2007).

9) J. J. Fripiat, Aluminas rehydration and dehydration. Mat Res Soc Symp Proc 1997; 432: 15-20.

10) D. Coster, A. L. Blumenfeld and J. J. Fripiat, J. Phys. Chem., 98, 6201-6211 (1994).

11) L. Vlaev, D. Damyanov and M. M. Mohamed, Colloids Surf., 36, 427-437 (1989).

12) T. Shirai, C. Ishizaki, M. Fuji and K. Ishizaki, $A d v$ Tech Mater and Mater Processing Journal, 13, 85-92 (2011) (ATM).

13) T. Shirai, Ch. Ishizaki and K. Ishizaki, Interceram, 50, 176181 (2001).

14) T. Shirai, J. W. Li, K. Matsumaru, C. Ishizaki and K. Ishizaki, Sci. Technol. Adv. Mater., 6, 123-128 (2005).

15) T. Shirai, C. Ishizaki and K. Ishizaki, J. Ceram. Soc. Japan, 114, 286-289 (2006).

16) T. Shirai, C. Ishizaki and K. Ishizaki, J. Ceram. Soc. Japan, 114, 415-417 (2006). 